\title{
Densidade, caracterização e eficiência de bactérias fixadoras de Nitrogênio em áreas de caatinga degradada
}

\section{Density, characterization and efficiency of Nitrogen fixing bacteria in areas of degraded caatinga}

\author{
Aldênia Mendes Mascena de Almeida ${ }^{{ }^{*}}$, Paulo Furtado Mendes Filho², Kaio Gráculo Vieira Garcia ${ }^{3}$, Vânia Felipe Freire \\ Gomes ${ }^{4}$, Cicero Lima de Almeida ${ }^{5}$
}

\begin{abstract}
Resumo: A degradação do solo resultante de práticas não conservacionistas pode acarretar prejuízos irreparáveis às propriedades químicas e biológicas do sistema edáfico de regiões Semiáridas do Nordeste brasileiro. O objetivo do trabalho foi avaliar os atributos químicos do solo, estimando a densidade populacional de rizóbios nativos e isolando estirpes eficientes na fixação simbiótica do $\mathrm{N}_{2}$ no feijão-caupi em áreas de exclusão e de superpastejo. $\mathrm{O}$ estudo foi realizado na Fazenda Formigueiro, pertencente ao município de Irauçuba Ceará. As coletas do solo foram realizadas em duas áreas caracterizadas por diferentes níveis de degradação, sendo: área de exclusão e área de superpastejo. O delineamento experimental adotado foi inteiramente casualizado com oito tratamentos e quatro repetições, sendo um controle com adição de nitrogênio mineral $\mathrm{C}$ (+N-R); e um com omissão de nitrogênio mineral e ausência de inoculação C (-N-R), totalizando 32 unidades experimentais. O uso intensivo do solo e o histórico de manejo das áreas estudadas contribuíram de forma negativa para as propriedades químicas e densidade de células rizobianas. $\mathrm{O}$ estudo da eficiência fixadora de $\mathrm{N}_{2}$ das estirpes nativas nas áreas de exclusão e superpastejo evidenciaram a ocorrência de estirpes com eficiência variável, apresentando uma eficácia simbiótica em torno de 22 a $41 \%$ para a cultura do feijão-caupi.
\end{abstract}

Palavras-chave: Solo; Semiárido; Degradação; Estirpes; Feijão-caupi.

\begin{abstract}
Soil degradation resultant from non-conservation practices may lead to irreparable damage to the chemical and biological properties of the soil system of semi-arid regions of northeastern Brazil. The aim of this work was to evaluate soil chemical attributes, estimate the population density of native rhizobia strains and isolate efficient strains in symbiotic $\mathrm{N}^{2}$ fixation in the cowpea bean in exclusion of super grazing areas. The study was carried out at Farm Formigueiro, located in the municipality of Irauçuba, Ceará, Brazil. The soil samples were collected in two areas characterized by different levels of degradation, being: i) area of exclusion and ii) area of super grazing. The experimental design was completely randomized with eight treatments and four replications, being a control with addition of mineral nitrogen $\mathrm{C}(+\mathrm{N}-\mathrm{R})$; and one with omission of mineral nitrogen and absence of $\mathrm{C}(-\mathrm{N}-\mathrm{R})$ inoculation, totalizing 32 experimental units. The intensive use of the soil and the management history of the studied areas contributed negatively to the chemical properties and density of rhizobian cells. The study of the $\mathrm{N}_{2}$ fixing efficiency of the native strains in the exclusion and super pasture areas evidenced the occurrence of strains with variable efficiency, presenting a symbiotic efficacy around 22 to $41 \%$ for the cowpea beans.
\end{abstract}

Key-words: Soil; Semi-arid; Degradation; Strains; Cowpea bean

\footnotetext{
*Autor para correspondência

Recebido para publicação em 27/09/2017; aprovado em 08/12/2017

${ }^{1}$ Doutora em Ciências do Solo, Universidade Federal do Ceará, Campus do PICI, Fortaleza, Ceará; ald_m_m@hotmail.com

${ }^{2}$ Professor Titular Dr., Departamento de Ciências do Solo, Universidade Federal do Ceará, Campus do PICI, Fortaleza, Ceará; mendes@ufc.br

${ }^{3}$ Doutorando em Ciências do Solo, Universidade Federal do Ceará, Campus do PICI, Fortaleza, Ceará; kaiovieira88@hotmail.com

${ }^{4}$ Professora Titular Dra., Departamento de Ciências do Solo, Universidade Federal do Ceará, Campus do PICI, Fortaleza, Ceará; vaniafreire@ ufc.br

${ }^{5}$ Doutor em Engenharia Agrícola, Universidade Federal do Ceará; climaal@ hotmail.com
} 


\section{INTRODUÇÃO}

O semiárido nordestino corresponde aproximadamente a 1 milhão de $\mathrm{km}^{2}$ com uma população de cerca de 20 milhões de habitantes (SAMPAIO et al., 2005), sendo uma região caracterizada por altas temperaturas, baixa pluviosidade, solos poucos desenvolvido e pequena produção de biomassa vegetal em virtude das características da vegetação. Além dessas condições edafoclimáticas peculiares, observa-se a adoção de sistemas agrícolas totalmente intensivo (AGUIAR et al., 2006), com mudanças negativas no uso dos recursos naturais, como é o caso de Irauçuba no Estado do Ceará.

A ação antrópica sobre os ecossistemas do semiárido nordestino se manifesta na exploração de três atividades, quais sejam, agricultura, pecuária e extração de madeira, todas exploradas com ausência de um manejo conservacionista, afetando diretamente os recursos naturais renováveis da caatinga, sendo que na pecuária predomina o superpastejo das áreas por animais de médio e grande porte (ARAÚJO FILHO et al., 2007).

A degradação das pastagens tornou-se um dos principais sinais da baixa sustentabilidade da pecuária nas diferentes regiões brasileiras. O principal fator que vem contribuindo para essa degradação é o manejo inadequado do rebanho nas áreas de pastagem. Fogel et al. (2013) comentam que o sistema intensivo adotado na maioria das áreas de pecuária bovina no Brasil vem gerando uma degradação ambiental ocasionada pela má utilização dos recursos naturais (solo, vegetação e água), sendo o solo o recurso mais afetado, devido à ausência da reposição de nutrientes e da matéria orgânica.

A retirada da cobertura do solo para a implantação de sistemas agrícolas em regiões de clima semiárido, como ocorre em Irauçuba-CE, leva à uma diminuição no aporte de matéria orgânica depositada na superfície do solo pela vegetação, provocando uma diminuição dos nutrientes do solo, o que resulta em impactos negativos (enfraquecimento da vegetação, desagregação e empobrecimento do solo e redução da sua biodiversidade).

Uma alternativa economicamente viável na recuperação de solos degradados pela ausência de práticas conservacionistas é a utilização da cultura do feijão-caupi, pois além de ser fonte de alimento para a população (ZILLI et al., 2013), é também uma leguminosa importante para a revegetação e recuperação de áreas degradadas, pois ela acaba por proporcionar melhores condições para que outras espécies vegetais possam se desenvolver nesses ambientes em reabilitação. Isto se deve, em grande parte, à capacidade do feijão-caupi em estabelecer relação simbiótica com bactérias do gênero Rhizobium, as quais são capazes de fixar o nitrogênio atmosférico $\left(\mathrm{N}_{2}\right)$.

O aumento dessas áreas cultiváveis com o feijão-caupi pode estar correlacionado com a associação dessa leguminosa com rizóbios, o que reduziria consideravelmente os gastos dos produtores com adubação nitrogenada, além de ser fonte de nitrogênio ao solo. Portanto, é necessário que os pesquisadores na área de microbiologia do solo busquem alternativas para o uso mais efetivo desses micro-organismos na agricultura, sugerindo uma maior oferta de inoculantes comerciais eficientes as nossas condições edafoclimáticas do semiárido.

Com base no exposto, o objetivo deste trabalho foi avaliar os atributos químicos do solo, estimando a densidade populacional de rizóbios nativos e isolando estirpes eficientes na fixação simbiótica do $\mathrm{N}_{2}$ no feijão-caupi em áreas de exclusão (preservadas) e de superpastejo (pecuária extensiva).

\section{MATERIAL E MÉTODOS}

O estudo foi realizado na Fazenda Formigueiro, pertencente ao município de Irauçuba-CE. O clima da região é do tipo Tropical Quente Semiárido, com uma média de precipitação anual de $518 \mathrm{~mm}$ e temperaturas médias de $28^{\circ} \mathrm{C}$, apresentando solos geralmente rasos e pobres em nutrientes e de características físicas e morfológicas favoráveis à erosão (DIAS, 1998; IBGE, 2014; IPECE, 2011).

As coletas do solo foram realizadas em duas áreas caracterizadas por diferentes níveis de degradação, sendo: área de exclusão (permanece em processo de regeneração natural, livre da entrada de animais domésticos) e área de superpastejo (com pouca ou nenhuma vegetação natural e severa presença de erosão laminar). Em cada área foram coletadas amostras de solo em triplicata, a uma profundidade de $0-20 \mathrm{~cm}$. O solo ocorrente em ambas as áreas foi classificado como PLANOSSOLO NÁTRICO Órtico Vertissólico (EMBRAPA, 2006). As características químicas de cada área foram determinadas conforme a metodologia descrita pela EMBRAPA (1997) e encontram-se presentes na Tabela 1.

Tabela 1. Características químicas do PLANOSSOLO NÁTRICO Órtico Vertissólico em áreas de exclusão de animais e de superpastejo. Fazenda Formigueiro, Irauçuba, Ceará

\begin{tabular}{cccccccc}
\multirow{2}{*}{ Áreas } & $\mathrm{pH}$ & $\mathrm{CE}$ & $\mathrm{C}$ & $\mathrm{N}$ & $\mathrm{C} / \mathrm{N}$ & $\mathrm{MO}$ & $\mathrm{P}$ \\
\cline { 2 - 8 } & $\mathrm{H}_{2} \mathrm{O}$ & $\mathrm{dS} \mathrm{m}^{-1}$ & $\mathrm{~g} / \mathrm{kg}$ & $\mathrm{g} / \mathrm{kg}$ & & $\mathrm{g} / \mathrm{kg}$ & $\mathrm{mg} / \mathrm{kg}$ \\
\hline${ }^{1} \mathrm{Exc}$ & 5 & 0,63 & 6,72 & 0,64 & 11 & 11,59 & 54 \\
${ }^{2}$ Sup & 5 & 0,7 & 4,86 & 0,49 & 10 & 8,38 & 42
\end{tabular}

${ }^{1}$ Exclusão, ${ }^{2}$ Superpastejo. $\mathrm{CE}=$ condutividade elétrica do solo; $\mathrm{C}=$ carbono; $\mathrm{N}=$ nitrogênio; $\mathrm{C} / \mathrm{N}=$ relação carbono e nitrogênio; $\mathrm{MO}=$ matéria orgânica do solo; P assimilável-=fósforo assimilável.

\section{Isolamento, purificação e caracterização dos rizóbios}

A planta-isca utilizada foi o feijão-caupi (Vigna unguiculata (L.) Walp.), variedade Sempre Verde CE 25, safra 2010, cujas sementes foram provenientes do Laboratório de Sementes do Departamento de Fitotecnia da Universidade Federal do Ceará (UFC). Antes da semeadura as sementes foram desinfestadas por imersão em álcool etílico $75 \%$ durante três minutos, e posteriormente foram imersas em hipoclorito de sódio (10\% por 10 minutos), e em seguida, lavadas cinco vezes em água destilada esterilizada para remoção do excesso de hipoclorito de sódio (HUNGRIA; ARAÚJO, 1994). O plantio das sementes foi realizado em vasos com capacidade para $500 \mathrm{~mL}$ contendo $400 \mathrm{~g}$ de solo, adotando-se quatro repetições para o solo de cada área utilizado (superpastejo e exclusão).

Aos 35 dias após a semeadura os nódulos foram coletados e tratados superficialmente com uma solução de hipoclorito de sódio (10\% por 10 minutos), lavados em água estéril por cinco vezes, e posteriormente foram esmagados e estriados em placas de Petri contendo meio "79" (ALLEN, 1957) com corante vermelho congo (1\%), usado com a finalidade inicial de evidenciar alguma contaminação. Posteriormente as placas foram incubadas na ausência de luz em estufa bacteriológica a $28^{\circ} \mathrm{C}$ até a formação de colônias visíveis mais claras pela não absorção do vermelho congo. 
Aos 12 dias da formação das colônias, estas foram repicadas para uma placa contendo meio "79" (ALLEN, 1957) sólido com indicador azul de bromotimol e incubadas sob condições controladas. Após esse período, estas foram caracterizadas morfologicamente conforme Vicent (1970) onde foram avaliadas em tamanho, cor, elevação, presença de muco, reação a técnica de Gram, $\mathrm{pH}$ do meio, forma e tempo de crescimento.

\section{Autenticação}

Os isolados foram submetidos a teste de autenticidade por meio do plantio e inoculação dos isolados em plantas de feijão-caupi. Para isso, realizou-se o preparo de um substrato composto de areia autoclavada $\left(121^{\circ} \mathrm{C}\right.$ a 1 atm de pressão por duas horas). $\mathrm{O}$ plantio das sementes de feijão-caupi (variedade sempre verde CE25) foi realizado em vasos com capacidade para $500 \mathrm{~mL}$ contendo $400 \mathrm{~g}$ de substrato (areia), adotando-se quatro repetições por isolados. Antes do plantio, as sementes passaram por um processo de desinfestação conforme Hungria e Araújo (1994).

Para obtenção dos inóculos foi adicionado $50 \mathrm{~mL}$ do meio de cultura "79" (ALLEN, 1957) contendo azul de bromotimol em enlenmeyeres de $125 \mathrm{~mL}$ que em seguida recebeu uma pequena porção da cultura pura de cada isolado e foi mantido sob agitação até atingirem uma concentração de 109 células por $\mathrm{mL}$ de caldo. Em seguida foram aplicados 3 $\mathrm{mL}$ do caldo rizobiano nas sementes por ocasião do plantio e mais $3 \mathrm{~mL}$ foram aplicados no colo das plântulas após 5 dias da emergência, como reforço. Aos 35 dias após o plantio as plantas foram analisadas quanto a presença (positivo) ou ausência (negativo) de nódulos radiculares. Os isolados com autenticidade confirmada (presença de nódulos radiculares) foram incorporados a coleção de cultura de bactérias diazotróficas do Laboratório de Microbiologia do Solo (LMBS), pertencente ao Departamento de Ciência do Solo (DCS) da Universidade Federal do Ceará (UFC).

\section{Avaliação da eficiência dos isolados na fixação simbiótica de nitrogênio}

Os isolados selecionados e autenticados anteriormente foram avaliados quanto à eficiência na fixação simbiótica de nitrogênio em experimento realizado em casa de vegetação, em vasos de "Leonard" (VICENT, 1970). Foram selecionados para o estudo com feijão-caupi seis isolados da Fazenda Formigueiro, município de Iraúçuba-CE. As estirpes 1, 2 e 3 foram provenientes da área de exclusão e as 4, 5 e 6 da área de superpastejo (conforme descrito anteriormente).

O substrato utilizado foi uma areia lavada e autoclavada por um período de 2 horas, com o intuito de eliminar o excesso de sais e qualquer tipo de biota nativa. Foram utilizados vasos plásticos de $500 \mathrm{~mL}$ contendo $400 \mathrm{~g}$ de areia, onde foram semeadas três sementes de feijão-caupi por vaso, previamente desinfectadas. Após a semeadura, as sementes foram inoculadas com o caldo rizobiano de cada estirpe proveniente das áreas em estudo.

Para obtenção do caldo rizobiano concentrado foram transferidos assepticamente células rizobianas de cada estirpe para erlenmeyers de $80 \mathrm{~mL}$ contendo meio "79" de Allen líquido com azul de bromotimol e mantidos sob agitação até atingirem uma concentração de 109 células por mL de caldo, os quais foram aplicados no momento da semeadura. Após a emergência das plântulas, foram aplicados $3 \mathrm{~mL}$ do caldo rizobiano ao colo de cada plântula recém emergida para reforçar a inoculação.
Semanalmente as plantas receberam $150 \mathrm{~mL}$ da solução nutritiva de Hoagland e Arnon (1950) de forma fracionada (três vezes na semana), sendo que os tratamentos com inoculação receberam solução nutritiva com omissão de nitrogênio, enquanto que os tratamentos sem inoculação receberam solução nutritiva com nitrogênio. As plantas foram irrigadas diariamente com água destilada e estéril.

Aos 35 dias após a semeadura as plantas de feijão-caupi foram separadas em parte aérea e nódulos. As mesmas foram acondicionadas em sacos de papel identificados e submetidas à secagem em estufa de circulação forçada de ar à temperatura de $65{ }^{\circ} \mathrm{C}$ até atingir massa constante. Após a secagem a parte aérea e os nódulos foram pesados em balança analítica com $0,01 \mathrm{~g}$ de precisão para obtenção da massa seca.

Após a pesagem da parte aérea das plantas, as mesmas foram moídas para a determinação química do acúmulo de nitrogênio no tecido conforme Tedesco et al. (1995).

A EFR foi calculada através da seguinte formula: EFR = (MSPA/MSPA do controle com N mineral) x 100, onde EFR = eficiência relativa e MSPA = matéria seca da parte aérea.

$\mathrm{O}$ delineamento experimental utilizado foi o inteiramente casualizado com oito tratamentos (Estirpe 1; Estirpe 2; Estirpe 3; Estirpe 4; Estirpe 5; Estirpe 6; $\mathrm{C}(+\mathrm{N}-\mathrm{R})$; $\mathrm{C}(-\mathrm{N}-\mathrm{R}))$ e quatro repetições, sendo um controle com adição de nitrogênio $(\mathrm{N})$ mineral $\mathrm{C}(+\mathrm{N}-\mathrm{R})$ e um com omissão de $\mathrm{N}$ mineral e ausência de inoculação $\mathrm{C}(-\mathrm{N}-\mathrm{R})$, totalizado 32 unidades experimentais. Os dados foram submetidos a análise de variância e as médias foram comparadas entre si pelo teste de Tukey $(p \leq 0,01)$, utilizando-se o programa estatístico ASSISTAT versão 7.6 Beta (SILVA, 2013).

\section{RESULTADOS E DISCUSSÃO}

Em relação à densidade de células de rizóbios no solo (Tabela 2), pode-se observar que a área de exclusão apresentou valores superiores (98 células/g solo) em relação a área de superpastejo (50 células/g solo), demonstrando assim que a preservação do solo e o restabelecimento inicial dos micro-organismos nativa na área de exclusão influenciaram de maneira positiva no aumento de células rizobianas viáveis no solo. Estes resultados corroboram com os obtidos por Sene et al. (2012) ao estudarem a abundância de rizóbios em solos de áreas degradadas e em sistemas florestais no semiárido do Senegal. Segundo estes autores, solos sob sistemas florestais apresentaram um maior número de células rizobianas viáveis quando comparado a solos degradados.

Tabela 2. Densidade de células rizobianas no solo das áreas de exclusão e de superpastejo. Fazenda Formigueiro, Irauçuba, Ceará.

\begin{tabular}{cc}
\hline Áreas & NMP de células viáveis por grama de solo \\
\hline Exclusão & 98 células $/ \mathrm{g}_{\text {solo }}$ \\
Superpastejo & 51 células $/ \mathrm{g}_{\text {solo }}$ \\
\hline NMP= número mais provável de células viáveis no solo.
\end{tabular}

A baixa densidade de células viáveis na área de superpastejo pode ser atribuída às características químicas desse solo (Tabela 1) e à ausência de vegetação na área, o que induz os rizóbios a adaptarem-se às condições saprofíticas, ocorrendo eventualmente perda do material genético envolvido na qualidade da fixação biológica do $\mathrm{N}_{2}$. Segundo alguns autores (ZILLI et al., 2013; MARTINS et al., 2011; HUNGRIA; VARGAS, 2000) as condições de fertilidade e 
pH da solução do solo podem deprimir e dificultar o crescimento dos rizobios no solo.

Ali et al. (2009) relatam que as células rizobianas crescem melhor em uma faixa de $\mathrm{pH}$ que varia entre 6,0 e 7,0, sendo poucas estirpes a apresentarem um bom crescimento em $\mathrm{pH}$ menor que 5,0.
Ao concluir a caracterização cultural (Tabela 3), observou-se que as seis estirpes rizobianas isoladas da área de exclusão e superpastejo apresentaram crescimento rápido (3 dias), bem como elevada produção de muco e acidificação após as repicagens em placas de Petri contendo meio "79" de Allen sólido com o indicador azul de bromotimol.

Tabela 3. Características culturais das estirpes isolados e autenticadas para a cultura do feijão-caupi provenientes de áreas de exclusão e superpastejo.

\begin{tabular}{lcccccccccc}
\hline \multirow{2}{*}{ Estirpes } & \multicolumn{10}{c}{ Características culturais das colônias } \\
\cline { 2 - 10 } & FAA & TC & CC & TR & EL & FC & FM & EM & OR & GRAM \\
\hline Estirpe 1 & $\mathrm{Ac}$ & $\mathrm{R}$ & $\mathrm{H}$ & $\mathrm{T}$ & $\mathrm{C}$ & $\mathrm{I}$ & $\mathrm{P}$ & $\mathrm{PF}$ & EXC. & NEG. \\
Estirpe 2 & $\mathrm{Ac}$ & $\mathrm{R}$ & $\mathrm{H}$ & $\mathrm{T}$ & $\mathrm{C}$ & $\mathrm{I}$ & $\mathrm{P}$ & $\mathrm{PF}$ & EXC. & NEG. \\
Estirpe 3 & $\mathrm{Ac}$ & $\mathrm{R}$ & $\mathrm{H}$ & $\mathrm{T}$ & $\mathrm{C}$ & $\mathrm{I}$ & $\mathrm{P}$ & $\mathrm{PF}$ & EXC. & NEG. \\
Estirpe 4 & $\mathrm{Ac}$ & $\mathrm{R}$ & $\mathrm{H}$ & $\mathrm{T}$ & $\mathrm{C}$ & $\mathrm{I}$ & $\mathrm{P}$ & $\mathrm{PF}$ & SUP. & NEG. \\
Estirpe 5 & $\mathrm{Ac}$ & $\mathrm{R}$ & $\mathrm{H}$ & $\mathrm{T}$ & $\mathrm{C}$ & $\mathrm{I}$ & $\mathrm{P}$ & $\mathrm{PF}$ & SUP. & NEG. \\
Estirpe 6 & $\mathrm{Ac}$ & $\mathrm{R}$ & $\mathrm{H}$ & $\mathrm{O}$ & $\mathrm{C}$ & $\mathrm{I}$ & $\mathrm{P}$ & $\mathrm{PF}$ & SUP. & NEG. \\
\hline
\end{tabular}

FAA - formação de ácido (Ac: ácida); TC - tempo de crescimento (R: rápido); CC - cor das colônias (H: Hialina); TR - transparência (O: opaca, T: translúcida); EL - elevação (C: convexa); FC - forma das colônias (I: Irregular); FM- formação de muco (P: presente); EM - elasticidade do muco (PF: presença de fio); OR - Origem (EXC - exclusão; SUP -superpastejo); GRAM (negativo).

Geralmente o crescimento rápido, a produção de muco elevado e acidificação do meio de cultivo são características apresentadas por estirpes de ambientes com pouca umidade, como é o caso do solo de Irauçuba-CE, que é uma região de baixa precipitação pluviométrica e clima semiárido. Essas estirpes apresentam maior tolerância a períodos secos e se multiplicam rapidamente no solo quando encontram condições ideais de temperatura, umidade e $\mathrm{pH}$.

De acordo com Medeiros et al. (2009), a presença de rizóbios que apresentam crescimento rápido é comum em regiões áridas e semiáridas devido a maior necessidade de uma rápida multiplicação para a perpetuação das espécies em solos de baixa umidade. Outra evidencia de adaptação é a produção de muco, uma vez que vem sendo descrita por vários autores (ARAÚJO; GUALTER, 2017) como um mecanismo de adaptação e sobrevivência as condições do meio. Teixeira et al. (2010) trabalhando com rizóbios nativos da caatinga encontraram 61 estirpes de crescimento rápido e seis de crescimento lento. Esses resultados reforçam ainda mais os encontrados nesse trabalho, onde as seis estirpes apresentaram crescimento rápido e acidificação do meio de cultivo. Resultados semelhantes também foram observados por Santos et al. (2007) ao estudarem a diversidade de rizóbios capazes de nodular leguminosas tropicais.

No que diz respeito a acidificação do meio de cultivo proporcionado pelas estirpes, Tan e Broughton (1981) sugerem que essa alteração do pH no meio de cultivo é promovida pela utilização preferencial das estirpes de crescimento rápido pelos açúcares presentes no meio de cultura e pela excreção de ácidos orgânicos após o consumo desse açúcar.

As seis estirpes rizobianas autenticadas e inoculadas nas plantas de feijão-caupi por ocasião da semeadura contribuíram para a produção da MSPA, com uma Efr ao controle adubado com $\mathrm{N}$ mineral $(100 \%)$ variando de 22 a 41 $\%$ (Tabela 4). A estirpe 5 apresentou uma baixa Efr (22\%) em relação às demais estirpes inoculadas, apesar do TNPA não diferir estatisticamente das estirpes 3, 4 e 6 . A estirpe 1 apresentou os maiores valores de Efr (41\%), TNPA (3,46 g) e MSN $(0,19 \mathrm{~g})$, proporcionado uma maior eficiência em relação as demais estirpes. Matoso e Kusdra (2014) relatam que os efeitos da inoculação rizobiana na cultura do feijão é bastante variável e divergente, visto que a espécie não é seletiva.

Lima et al. (2005) relatam que populações nativas de rizóbios são constituídas por grande diversidade de estirpes, com eficiência simbiótica variável, algumas das quais podem ser recomendadas para testes de eficiência agronômica. De acordo com Rufini et al. (2014) a eficiência simbiótica é afetada por diversos fatores (temperatura, $\mathrm{pH}$, salinidade, umidade e outros) que podem comprometer o desempenho das estirpes inoculadas em feijão-caupi.

Tabela 4. Eficiência da fixação simbiótica relativa do nitrogênio atmosférico em feijão-caupi inoculado com seis estirpes de rizóbios provenientes das áreas de exclusão e superpastejo.

\begin{tabular}{|c|c|c|c|c|}
\hline Estirpes & MSPA & TNPA & MSN & Efr \\
\hline & --- & --------- & -------------- & --------- \% -------- \\
\hline Estirpe 1 & $33,65 \mathrm{~B}$ & $3,46 \mathrm{~A}$ & $0,19 \mathrm{~A}$ & $41 \mathrm{~A}$ \\
\hline Estirpe 2 & $34,32 \mathrm{~B}$ & $0,09 \mathrm{D}$ & $0,14 \mathrm{AB}$ & $38 \mathrm{~A}$ \\
\hline Estirpe 3 & $36,40 \mathrm{~B}$ & $1,39 \mathrm{~B}$ & $0,16 \mathrm{~A}$ & $39 \mathrm{~A}$ \\
\hline Estirpe 4 & $37,52 \mathrm{~B}$ & $1,34 \mathrm{~B}$ & $0,14 \mathrm{AB}$ & $39 \mathrm{~A}$ \\
\hline Estirpe 5 & $24,42 \mathrm{C}$ & $1,35 \mathrm{~B}$ & $0,10 \mathrm{~B}$ & $22 \mathrm{~B}$ \\
\hline Estirpe 6 & $32,55 \mathrm{~B}$ & $1,35 \mathrm{~B}$ & $0,18 \mathrm{~A}$ & $38 \mathrm{~A}$ \\
\hline $\mathrm{C}(+\mathrm{N}-\mathrm{R})$ & $74,07 \mathrm{~A}$ & $0,77 \mathrm{C}$ & Sem nódulos & - \\
\hline $\mathrm{C}(-\mathrm{N}-\mathrm{R})$ & $5,82 \mathrm{D}$ & $1,34 \mathrm{~B}$ & Sem nódulos & - \\
\hline $\mathrm{CV}(\%)$ & 8,80 & 4,52 & 20,44 & 5,12 \\
\hline
\end{tabular}


Além disso, o processo de fixação biologica $\mathrm{N}_{2}$ é influenciado pelas caracteristicas genotípicas do macro e do microssimbionte, refletindo nas diversas respostas em relação à planta hospedeira, especificidade e eficiência simbiótica das estirpes testadas (COSTA et al., 2011).

$\mathrm{O}$ estudo da eficiência fixadora de $\mathrm{N}_{2}$ nas estirpes nativas das regiões semiáridas para cultura do feijão-caupi tem evidenciado a ocorrência de uma grande variabilidade funcional, fato esse que possivelmente esteja relacionado à alta capacidade dessa espécie vegetal em associar-se com diversas espécies de bactérias nativas fixadoras simbióticas do $\mathrm{N}_{2}$, incluindo os gêneros Azorhizobium, Burkholderia, Bradyrhizobium, Mesorhizobium, Rhizobium, Sinorhizobium, entre outros (MOREIRA, 2008). Alcantara et al. (2014) também confirmaram que nas leguminosas a fixação biológica de $\mathrm{N}_{2}$ é bastante variável e depende também das espécies das bactérias simbióticas envolvidas. A associação simbiótica de feijão-caupi com bactérias fixadoras de $\mathrm{N}_{2}$ pode aumentar a produtividade e diminuir os custos de produção em virtude da redução do uso de fertilizantes nitrogenados (SOARES et al., 2006).

No entanto, as estirpes selecionadas em casa de vegetação podem não apresentar o mesmo potencial de fixação de $\mathrm{N}_{2}$ no campo, em virtude de fatores ambientais adversos como a competição com a população nativa rizobiana, adaptações às condições ambientais locais (temperatura, umidade e $\mathrm{pH}$ ) e à própria promiscuidade do feijão-caupi. Santos et al. (2007) descrevem que condições ambientais adversas (temperatura ou baixa precipitação) podem afetar a sobrevivência e a eficiência dos rizóbios em ambientes de clima semiárido.

O estudo dessas bactérias simbiontes nativas apresenta, portanto, grande importância ecológica e econômica, pois proporciona uma seleção de estirpes nativas eficientes e adaptadas às condições ambientais da região semiárida. De acordo com Radl et al. (2014), a prospecção de bactérias simbiontes que nodulam o feijão-caupi representa uma estratégia importante na região semiárida, pois é a etapa inicial para seleção de estirpes eficientes para produção de inoculantes comerciais para uso biotecnológico. Esse aspecto é fundamental nos sistemas de produção agrícola onde o aporte de tecnologia é baixo, como ocorre nas áreas de produção familiar.

\section{CONCLUSÕES}

O uso intensivo do solo e o histórico de manejo das áreas estudadas contribuíram de forma negativa para as propriedades químicas e densidade de células rizobianas;

$\mathrm{O}$ estudo da eficiência fixadora de $\mathrm{N}_{2}$ das estipes nativas nas áreas de exclusão e superpastejo evidenciaram a ocorrência de estipes com eficiência variável, apresentando uma eficácia simbiótica em torno de 22 a $41 \%$ para a cultura do feijão caupi.

\section{REFERÊNCIAS}

ALCANTARA, R. M. C. M. de; XAVIER, G. R; RUMJANEK, N. G.; ROCHA, M de M.; CARVALHO, J. dos S. Eficiência simbiótica de progenitores de cultivares brasileiras de feijão-caupi. Revista Ciência Agronômica, v. 45 , n. 1, p. 1-9, 2014.
ALI, S. F.; RAWAT, L. S.; MEGHVANSI, M. K.; MAHNA, S. K. Selection of stress-tolerant rhizobial isolates of wild legumes growing in dry regions of Rajasthan, India. Journal of Agricultural and Biological Science, v.4, p.13-18, 2009.

ALEXANDDER, M. Most probable number method for microbial populations. In: BLACK, C. A., ed. Methods of Soil analysis - Chemical and microbiological properties. Madison, American Society of Agronomy, v.2, p.1467-1472, 1965.

ARAÚJO, C. L. de; GUALTE, R. M. R. Caracterização morfoisiológica de bactérias nativas de solos do Cerrado isoladas de nódulos de feijão-caupi. Biotemas, v.30, n.1, p.2535, 2017.

ARAÚJO FILHO, J. A. SOUSA, F. B. de; SILVA, N. L. da; BEZERRA, T. S. Avaliação de leguminosas arbóreas, para recuperação de solos e repovoamento em áreas degradadas, Quixeramobim-CE. Revista Brasileira de Agroecologia, v.2, n.2, p.1592-1595, 2007.

AGUIAR, M. I. de; MAIA, S. M. F.; OLIVEIRA, T. S. de; MENDONÇA, E. S.; ARAUJO FILHO, J. A. Perdas de solo, água e nutrientes em sistemas agroflorestais no município de Sobral, CE. Revista Ciência Agronômica, v.37, n.3, p.270278, 2006.

ALLEN, O. N. Experiments in Soil Bacteriology, 3 ed., 1957, $177 \mathrm{p}$.

COSTA, E. M. da. Atividade biológica e caracterização de estirpes rizobianas de feijão-caupi isoladas de solo do munícipio de Irauçuba/CE. 2013, 39. Monografia (Graduação em agronomia) Centro de Ciências Agrárias, Universidade Federal do Ceará, Fortaleza, 2013.

COSTA, E. M. Nodulação e produtividade de Vigna unguiculata (L.) Walp. por cepas de rizóbio em Bom Jesus, PI. Revista Ciência Agronômica, v. 42, n. 1, p. 1-7, 2011.

DIAS, R. L. F. Intervenção Públicas e Degradação Ambiental no Semi-Árido Cearense (O Caso de Irauçuba). Dissertação, (Mestrado no Programa Regional de Pós-Graduação em Desenvolvimento e Meio Ambiente - PRODEMA), Universidade Federal do Ceará, Fortaleza, 1998.

EMBRAPA. Empresa brasileira de agropecuária. Sistema brasileiro de classificação de solos; Centro Nacional de Pesquisa de Solos. 2. ed. 2006, 306 p.

EMPRAPA. Empresa brasileira de agropecuária. Manual de métodos de análise de solo; Centro Nacional de Pesquisa de Solos. 2. Ed., 1997, 212p.

FOGEL, G. F.; MARTINKOSKI, L.; MOKOCHINSKI, F. M.; GUILHERMETTI, P. G. C.; MOREIRA, V. S. Efeitos da adubação com dejetos suínos, cama de aves e fosfato natural na recuperação de pastagens degradadas. Revista Verde de Agroecologia e Desenvolvimento Sustentável, v. 8, n. 5, p. 66 $-71,2013$.

HUNGRIA, M.; VARGAS, M. A. T. Environmental factors affecting $\mathrm{N}_{2}$ fixation in grain legumes in the tropics, with an 
emphasis on Brazil. Field Crops Research, v.65, p.151-164, 2000 .

HUNGRIA, M.; ARAÚJO, R. S.; Manual de métodos empregados em estudos de microbiologia agrícola. EMBRAPA, 1994, 552.p.

HOAGLAND, D. R.; ARNON, D. I.; The water culture method of growing plants without soil, 32p, 1950.

IBGE: Instituto Brasileiro de Geografia e Estatística. Município de Irauçuba. Disponível em: <http://www.ibge.gov.br/home/>. Acesso em março de 2014.

IPECE, INSTITUTO DE PESQUISA E ESTRATÉGIA ECONÔMICA DO CEARÁ-. Perfil Básico Municipal Irauçuba. Secretaria do Planejamento e Coordenação. Fortaleza- CE. 2011.

RADL, V.; SIMÕES-ARAÚJO, J. L.; LEITE, J.; PASSOS, S. R.; MARTINS, L. M. V.; XAVIER, G. R.; RUMJANEK, N. G.; BALDANI, J. I.; ZILLI, J. E. Microvirga vignae sp. nov., a root nodule symbiotic bacterium isolated from cowpea grown in semi-arid Brazil. International Journal of Systematic and Evolutionary Microbiology, v.64, n.3, p.725-730, 2014.

LIMA, A. S.; PEREIRA, J. P. A. R.; MOREIRA, F. M. S. Diversidade fenotípica e eficiência de estirpes de Bradyrhizobium spp. de solos da Amazônia. Pesquisa Agropecuária Brasileira, v.40, p.1095-1104, 2005.

LOPES, J.; EVANGELISTA, A. R.; FORTES, C. A.; PINTO, J. C.; FURTINI NETO, A. E.; SOUZA, R. M. de. Nodulação e produção de raízes do estilosantes mineirão sob efeito de calagem, silicatagem e doses de fósforo. Ciência agrotécnica, v. 35 , n. 1, p. 99-107, 2011.

LOPES, A. S. Manual de fertilidade do solo. São Paulo: ANDA/POTAFOS, 1989, 153 p.

MATOSO, S. C. G.; KUSDRA, J. F. Nodulação e crescimento do feijoeiro em resposta à aplicação de molibdênio e inoculante rizobiano. Revista Brasileira de Engenharia Agrícola Ambiental, v.18, n.6, p.567-573, 2014.

MARTINS, A. F.; VARGAS, L. K.; LISBOA, B. B.; SAMPAIO, J. A. T.; ARAÚJO, J. H. B. de; TURCATEL, A. T.; DIEMER, G. D.; SÁ, E. L. S. de. Diversidade genética, tolerância aos fatores de acidez e eficiência simbiótica de rizóbios para cornichão de solos do Rio Grande do Sul. Revista Brasileira de Ciência do Solo, n.35, p.1855-1864, 2011.

MEDEIROS, E. V. de; MARTINS, C. M.; LIMA, J. A. M.; FERNANDES, Y. T. D.; OLIVEIRA, V. R. de; BORGES, W. L. Diversidade morfológica de rizóbios isolados de caupi cultivado em solos do estado do Rio Grande do Norte. Acta Scientiarum, v. 31, n. 3, p. 529-535, 2009.

MOREIRA, F. M. S. Bactérias fixadoras de nitrogênio que nodulam Leguminosae. In: MOREIRA, F. M. S.; SIQUEIRA, J. O.; BRUSSAARD, L. (Ed.). Biodiversidade do solo em ecossistemas brasileiros. Lavras: UFLA, p. 621-680, 2008.
RUFINI, M.; SILVA, M. A. P. da; FERREIRA, P. A. A.; CASSETARI, A. de S.; SOARES, B. L.; ANDRADE, M. J. B. de; MOREIRA, F. M. de S. Symbiotic efficiency and identification of rhizobia that nodulate cowpea in a Rhodic Eutrudox. Biology and Fertility of Soils, v. 50, p.115-122, 2014.

SANTOS, C. E. de R. e S.; STAMFORD, N. P.; NEVES, M. C. P.; RUNJANEK, N. G.; BORGES, W. L.; BEZERRA, R. V.; FREITAS, A. D. S. Diversidade de rizóbios capazes de nodular leguminosas tropicais. Revista Brasileira de Ciências Agrárias. v. 2, n.4, p.249-256, 2007.

SENE, G.; SAMBA-MBAYE, R.; THIAO, M.; KHASA, D.; KANE, A.; MANGA, A.; MBAYE, M. S.; SYLLA, S. N. The abundance and diversity of legume-nodulating rhizobia and arbuscular mycorrhizal fungal communities in soil samples from deforested and man-made forest systems in a semiarid Sahel region in Senegal. European Journal of Soil Biology, v. 52, p. 30-40, 2012.

SILVA, F. A. S. Assistat versão 7.7 beta, distribuição gratuita. 2013.

SIQUEIRA. O. J.; ANDRADE, A. T.; FAQUIN, V. O papel dos micro-organismos na disponibilização e aquisição de fósforo pelas as plantas. In. YAMADA, T.; ABDALLA, S. R. S. Fósforo na agricultura brasileira. Associação brasileira para pesquisa da potassa e do fosfato, 2004, p.117-156.

SAMPAIO, E. V. S. B.; ARAÚJO, M. do S. B.; SAMPAIO, Y. S. B. Impactos ambientais da agricultura no processo de desertificação no Nordeste do Brasil. Revista de Geografia (Recife), v. 22, n.1, p. 93-113, 2005.

SOARES, A. L. de L.; PEREIRA, J. P. A. R.; FERREIRA, P. A. A.; VALE, H. M. M. do; LIMA, A. S.; ANDRADE, M. J. B. de; MOREIRA, F. M. de S. Eficiência agronômica de rizóbios selecionados e diversidade de populações nativas nodulíferas em perdões (MG). I - caupi. Revista Brasileira de Ciências do Solo, v.30, p.795-802, 2006.

TEIXEIRA, F. C. P.; BORGES, W. L.; XAVIER, G. R; RUMJANEK, N. G. Characterization of indigenous rhizobia from Caatinga. Brazilian Journal of Microbiology, n.41, p. 201-208, 2010.

TAN. K. P.; BROUGHTO W. J. Rhizobia in tropical legumes-xiii. biochemical basis of acid and alkali reactions. Soil Biology and Biochemistry, v.13, p.389-393, 1981.

TEDESCO, M. J.; GIANELLO, C.; BISSANI, C. A.; BOHNEN, H.; VOLKWEISS, S. J. Análises de solo, plantas e outros materiais. 2.ed. Porto Alegre: UFRGS, Departamento de solos, 1995. 174 p. (Boletim Técnico, 5).

VINCENT, J. M. A manual for the practical study of rootnodule bacteria. Oxford, Blackwell Scientific, (International Biological Programme Handbook), 164p. 1970.

ZILLI, J. É.; PEREIRA, G. M. D.; FRANÇA JÚNIOR, I.; SILVA, K. da; HUNGRIA, M.; ROUWS, J. R. C. Dinâmica de rizóbios em solo do cerrado de Roraima durante o período de estiagem. Acta Amazonia, v.43, p. 153-160, 2013. 